\title{
Optimization of timing of insemination of dairy heifers inseminated with sex-sorted semen
}

\author{
Ricardo C. Chebel ${ }^{1,2 *}$ (1) and Thiago Cunha ${ }^{1}$ (]) \\ ${ }^{1}$ Department of Large Animal Clinical Sciences, University of Florida, Gainesville 32610 \\ ${ }^{2}$ Department of Animal Sciences, University of Florida, Gainesville 32608
}

\begin{abstract}
We hypothesized that delaying by approximately $12 \mathrm{~h}$ the artificial insemination (AI) of heifers with sex-sorted semen increases pregnancy per AI (P/AI). Holstein heifers $(\mathrm{n}=1,207)$ were fitted with a collar containing an automated estrus-detection device (HRLDn tags, SCR Engineers Ltd., Netanya, Israel) at 10.7 \pm 0.02 mo of age. Once they reached $330 \mathrm{~kg}$, heifers were enrolled in an ovulation synchronization protocol (5-d Cosynch + controlled internal drug release; Zoetis, Parsippany-Troy Hills, NJ). Study personnel recorded the heifers that were in estrus according to the DataFlow II software (SCR Engineers Ltd., Netanya, Israel) twice daily at 0500 and $1500 \mathrm{~h}$ from the day of the first $\mathrm{PGF}_{2 \alpha}$ (Estrumate; Merck Animal Health, Madison, NJ) injection to $72 \mathrm{~h}$ later. Heifers enrolled in the conventional (CONV) and early sex-sorted (SSEarly) semen treatments detected in estrus at 0500 and 1500 $\mathrm{h}$ were $\mathrm{AI}$ at 0600 and $1600 \mathrm{~h}$ of the same day, respectively. Heifers enrolled in the late sex-sorted (SSLate) semen treatment detected in estrus at 0500 and 1500 $\mathrm{h}$ were AI at $1600 \mathrm{~h}$ of the same day and $0600 \mathrm{~h}$ of the following day, respectively. All heifers not detected in estrus by $72 \mathrm{~h}$ after the first $\mathrm{PGF}_{2 \alpha}$ injection received a GnRH (Fertagyl; Merck Animal Health, Madison, NJ) injection at $0500 \mathrm{~h}$. Heifers in the CONV and SSEarly treatments were AI at fixed time at $0600 \mathrm{~h}$, whereas heifers in the SSLate treatment were AI at fixed time at $1600 \mathrm{~h}$. Among heifers detected in estrus, the ranges of the interval from the onset of estrus to AI were 3.6 to $28.5 \mathrm{~h}, 0.0$ to $25.5 \mathrm{~h}$, and 9.4 to $36.8 \mathrm{~h}$ for the CONV, SSEarly, and SSLate treatments, respectively. Among heifers AI at fixed time, the ranges of the interval from the $\mathrm{GnRH}$ injection to $\mathrm{AI}$ were $0 \mathrm{~h}$ for heifers in the CONV and SSEarly treatments and 8.5 to $11.7 \mathrm{~h}$ for heifers in the SSLate treatment. The P/AI at 62 $\pm 1 \mathrm{~d}$ after the first AI was greater for CONV (63.1

Received November 7, 2019.

Accepted January 13, 2020.

*Corresponding author: rcchebel@ufl.edu
\end{abstract}

$\pm 2.6 \%)$ compared with SSEarly $(43.3 \pm 2.6 \%)$ and SSLate $(44.8 \pm 2.7 \%)$. A greater percentage of heifers enrolled in the SSEarly $(65.8 \pm 2.5 \%)$ and SSLate $(70.0 \pm 2.5 \%)$ treatments produced a live female calf compared with the CONV treatment $(40.5 \pm 2.7 \%)$. When the values of 1-d-old female and male calves were USD $\$ 0$ and the cost of replacement heifers was $\$ 750$, the cost of raising heifers from enrollment to calving was lesser for the CONV treatment than the SSEarly treatment, but SSLate treatment did not differ from CONV and SSEarly treatments. When the values of a 1-d-old female calf $\geq \$ 130$ and 1 -d-old male calf $\geq \$ 30$ and the cost of replacement $\geq \$ 1,000$, no differences were observed among treatments in the cost from enrollment to calving. We conclude from this experiment that the P/AI with sex-sorted semen is not improved when insemination is delayed by approximately $12 \mathrm{~h}$.

Key words: sex-sorted semen, Holstein heifer, delayed insemination

\section{INTRODUCTION}

Sex is a genetic trait long sought after by the dairy industry because of the importance of females for production of milk and cash flow (Seidel, 2003). The development of sex-sorting technologies has resulted in wide adoption of sex-sorted semen in the dairy industry, despite the reduced pregnancy per artificial insemination (P/AI) of cattle inseminated with sexsorted semen (DeJarnette et al., 2010; Karakaya-Bilen et al., 2019). The reduced P/AI with sex-sorted semen is believed to be a consequence of the reduced inseminating dose compared with conventional semen and changes to sperm viability that occur during the sorting process (Carvalho et al., 2010). Recent experiments, however, demonstrated that spermatozoa DNA damage pre-sorting is greater than DNA damage of $\mathrm{X}$ - and Y-chromosome-sorted spermatozoa because the DNA-damaged spermatozoa are accumulated in the nonviable pool of cells (Gosálvez et al., 2011a,b). Nonetheless, it is widely accepted that the impairment of $\mathrm{P} / \mathrm{AI}$ with sex-sorted semen may not be overcome 
by simply increasing the number of spermatozoa per inseminating dose (DeJarnette et al., 2011; Thomas et al., 2019). Therefore, new strategies are necessary to improve $\mathrm{P} / \mathrm{AI}$ with sex-sorted semen to reduce the cost of its adoption to the producer.

The ideal interval from the onset of estrus to $\mathrm{AI}$ is based on the synchronous/chronological occurrence of estrus, insemination, capacitation of spermatozoa, ovulation, and fertilization. The optimal interval from the onset of estrus to AI with conventional semen is between 4 to $16 \mathrm{~h}$ (Dransfield et al., 1998; Stevenson et al., 2014). Recent observational studies have indicated that postponement (16 to $40 \mathrm{~h}$ after onset of estrus) of AI with sex-sorted semen of Holstein and Jersey heifers and Jersey cows improves P/AI compared with AI between 4 to $12 \mathrm{~h}$ after onset of estrus (Sá Filho et al., 2010; Sales et al., 2011; Bombardelli et al., 2016). It is believed that delayed AI with sex-sorted semen, which results in placement of semen in the reproductive tract of the female closer to ovulation, could be beneficial because of the fewer viable spermatozoa available in an inseminating dose. Although a shorter interval from AI to ovulation may negatively affect the capacitation of spermatozoa, evidence from a few experiments suggest that the sex-sorting process may induce capacitationlike changes in spermatozoa (Maxwell et al., 1996, 1998).

Recent developments in ovulation synchronization protocols for dairy heifers have yielded acceptable P/ AI (Lima et al., 2013; Silva et al., 2015). It is widely accepted that the ideal stage of the estrous cycle to start ovulation synchronization protocols is between $\mathrm{d} 5$ and 9 (Vasconcelos et al., 1999; Moreira et al., 2000). During this stage of the estrous cycle, follicles responsive to a GnRH-induced LH surge would be present, increasing the likelihood of ovulation; follicles would grow under elevated concentrations of progesterone; and luteolysis and ovulation would be synchronized by the exogenous $\mathrm{PGF}_{2 \alpha}$ and $\mathrm{GnRH}$, respectively, at the end of the protocol (Vasconcelos et al., 1999; Moreira et al., 2000; Cerri et al., 2009). Although Moreira et al. (2000) demonstrated that the ovarian responses of dairy heifers to GnRH given at different stages of the estrous cycle are similar to those observed in lactating dairy cows, little is known about the association between stage of the estrous cycle at the start of the ovulation synchronization protocol and $\mathrm{P} / \mathrm{AI}$ in dairy heifers. Understanding the association between the stage of the estrous cycle at the start of the ovulation synchronization protocol and P/AI may allow for the fine tuning of ovulation synchronization protocols for heifers and optimization of $\mathrm{P} / \mathrm{AI}$.

Our hypothesis was that delaying the insemination of Holstein heifers with sex-sorted semen in approxi- mately $12 \mathrm{~h}$ increases $\mathrm{P} / \mathrm{AI}$. A second hypothesis of this experiment was that the stage of the estrous cycle at the start of the ovulation synchronization protocol is associated with characteristics of estrus and $\mathrm{P} / \mathrm{AI}$. Thus, the objectives of the current experiment were to determine the effect of delaying the AI with sex-sorted semen on P/AI of Holstein heifers and cost of raising replacement heifers from enrollment in this experiment to first calving. In addition, we aimed to understand the association between initiating the ovulation synchronization protocol at different stages of the estrous cycle and P/AI.

\section{MATERIALS AND METHODS}

Animal care and handling were in accordance with the Guide for the Care and Use of Agricultural Animals in Research and Teaching (FASS, 2010) and the studies were approved by the Institutional Animal Care and Use Committee (protocol \#201710100).

\section{Animals, Management, and Automated Estrus- Detection System}

Holstein heifers $(\mathrm{n}=1,207)$ from a dairy located in southern Georgia were enrolled in this experiment from December 2017 to April 2018. Heifers were fitted with a collar containing an automated estrus-detection device (HR-LDn tags, SCR Engineers Ltd., Netanya, Israel) on the proximal third of the neck, immediately behind the left ear, at $10.7 \pm 0.0$ mo of age (range: 8.8 to 13.0 mo). Thereafter, heifers were weighed every 2 wk until they reached at least $330 \mathrm{~kg}$ when they were submitted to the ovulation synchronization protocol. The mean ( \pm SEM) interval from fitting the collars to the start of the ovulation synchronization protocol was $41.7 \pm 0.5$ d (range: 16 to $100 \mathrm{~d}$ ).

\section{Ovulation Synchronization Protocol, Estrus Detection, and Treatments}

Heifers were subjected to the 5-d Cosynch protocol with a controlled internal drug release (CIDR; Zoetis, Parsippany-Troy Hills, NJ) insert (Figure 1). From d -3 to $0\left[72 \mathrm{~h}\right.$ after the first $\mathrm{PGF}_{2 \alpha}$ (Estrumate; Merck Animal Health, Madison, NJ) injection], study personnel recorded the heifers that were in estrus according to the DataFlow II software (SCR Engineers Ltd., Netanya, Israel) twice a day at 0500 and $1500 \mathrm{~h}$. Heifers enrolled in the conventional (CONV) and early sexsorted semen (SSEarly) treatments detected in estrus at $0500 \mathrm{~h}$ were inseminated at $0600 \mathrm{~h}$ of the same day and those detected in estrus at $1500 \mathrm{~h}$ were inseminated at $1600 \mathrm{~h}$ of the same day. Heifers enrolled in the 
late sex-sorted semen (SSLate) treatment detected in estrus at $0500 \mathrm{~h}$ were inseminated at $1600 \mathrm{~h}$ of the same day and heifers detected in estrus at $1500 \mathrm{~h}$ were inseminated at $0600 \mathrm{~h}$ of the next day. All heifers not detected in estrus received a GnRH (Fertagyl; Merck Animal Health, Madison, NJ) injection at $0500 \mathrm{~h}$ of d 0 . Heifers in the CONV and SSEarly treatments were inseminated at fixed time starting at $0600 \mathrm{~h}$, whereas heifers in the SSLate treatment were inseminated at fixed time starting at $1600 \mathrm{~h}$. Heifers inseminated at detected estrus did not receive the final GnRH injection. Three sires were used for the first insemination and all sires were equally distributed across all treatments. Straws containing sex-sorted and conventional semen obtained from each sire were derived from contemporary ejaculates. The inseminating doses were $20 \times 10^{6}$ cells and $2 \times 10^{6}$ motile cells for CONV and sex-sorted treatments, respectively. The sires used for second and greater inseminations were in accordance to the genetic program of the collaborating herd, independent of treatment. Only 2 technicians inseminated heifers and they were equally distributed across all treatments.

After the first insemination, heifers were re-inseminated when detected in estrus by the automated estrus-detection device or by farm personnel based on visual observation. The contents of the uterus of heifers not detected in estrus by $30 \pm 1 \mathrm{~d}$ after a previous AI were examined by transrectal ultrasonography for pregnancy diagnosis. The estrous cycles of nonpregnant heifers were re-synchronized with the 5-d Cosynch protocol with a CIDR insert. Heifers diagnosed pregnant at $30 \pm 1 \mathrm{~d}$ after AI were re-examined by transrectal ultrasonography at $62 \pm 1 \mathrm{~d}$ after AI. Pregnancy loss was evaluated from $30 \pm 1$ to $62 \pm 1 \mathrm{~d}$ after the first insemination and from $62 \pm 1 \mathrm{~d}$ after the first insemination until calving.

One thousand ninety-six heifers were detected in estrus by the automated estrus-detection device $\leq 24 \mathrm{~d}$ before the start of the ovulation synchronization protocol. These heifers were classified as being in metestrus ( 1 to 4 d after estrus; $\mathrm{n}=219$ ), early diestrus ( 5 to 9 $\mathrm{d}$ after estrus; $\mathrm{n}=257$ ), mid diestrus (10 to $17 \mathrm{~d}$ after estrus; $\mathrm{n}=438$ ), and proestrus (18 to $24 \mathrm{~d}$ after estrus; $\mathrm{n}=182)$ at the start of the ovulation synchronization protocol. Sixteen heifers were detected in estrus $\geq 25 \mathrm{~d}$ before the start of the ovulation synchronization protocol (range: 25 to $40 \mathrm{~d}$ ), and 95 heifers were not detected in estrus before the start of the ovulation synchronization protocol.

\section{Partial Budget Analysis}

To determine the effects of treatment on cost per heifer enrolled in the experiment, we calculated incomes and expenditures from enrollment up to first calving. Fixed values were rearing cost (USD $\$ 2.50 / \mathrm{d}$ per heifer), cost of the ovulation synchronization protocol $(\$ 12.50 /$ protocol $)$, and cull value $(\$ 1.32 / \mathrm{kg})$. Cost of conventional semen varied from $\$ 5$ to $\$ 15 /$ dose and cost of sex-sorted semen varied from $\$ 5.75$ to $\$ 17.25$ / dose, replacement cost (value of a pregnant heifer approximately $60 \mathrm{~d}$ before expected calving date) varied from $\$ 750$ to $\$ 1,500$, value of a 1-d-old female calf varied from $\$ 0$ to $\$ 260$, and value of a 1-d-old male calf varied from $\$ 0$ to $\$ 60$. These values were based on the previous $2 \mathrm{yr}$ of data from the collaborating herd.

The overall cost for each heifer enrolled in the experiment was calculated according to the cost of the

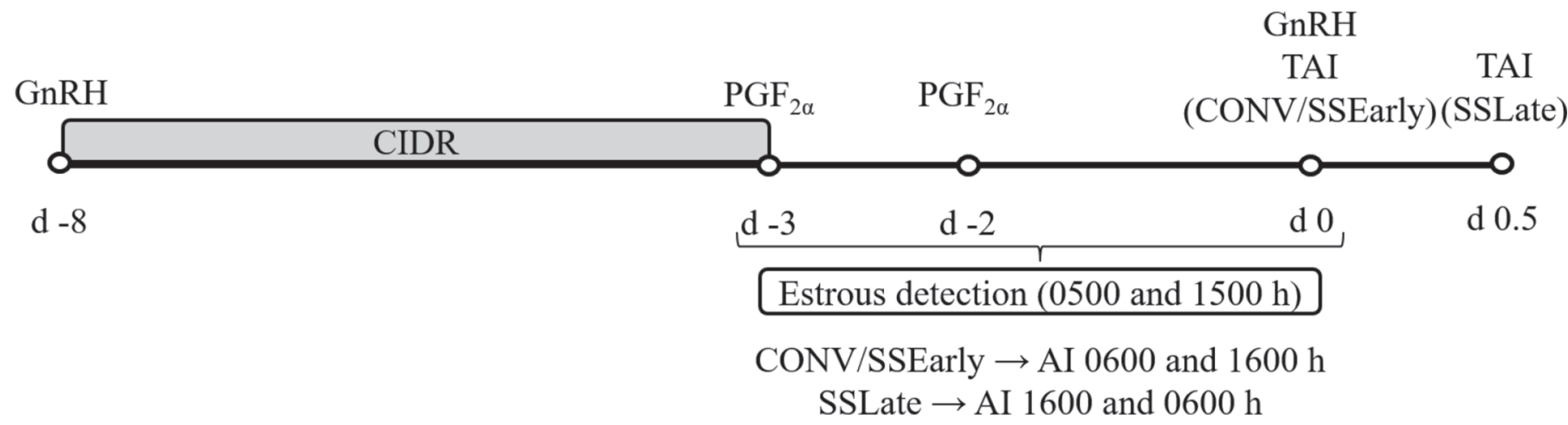

Figure 1. Experimental design. 5-d Cosynch protocol with a controlled internal drug release (CIDR; Zoetis, Parsippany-Troy Hills, NJ) in-

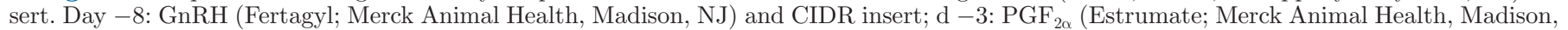

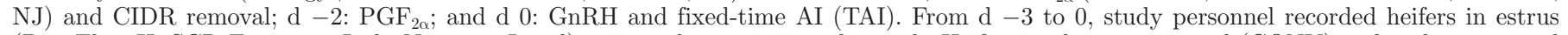
(DataFlow II, SCR Engineers Ltd., Netanya, Israel) twice a day at 0500 and 1500 h. Heifers in the conventional (CONV) and early sex-sorted

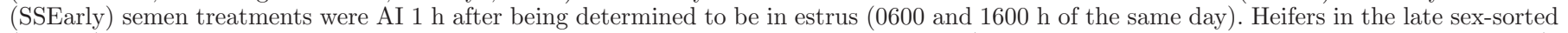

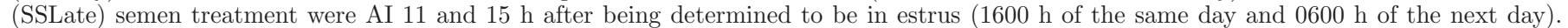

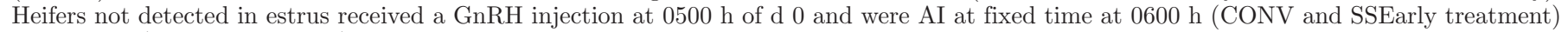
and $1600 \mathrm{~h}$ (SSLate treatment) of the same day. 
reproductive program, cost of rearing from enrollment in the experiment to calving or removal from the herd, cull value, cost of replacing heifers that were sold and died, and value of a live 1-d-old female and male calf. Cost of the reproductive program accounted for differences in cost of semen for the first insemination according to treatments, cost of semen for re-inseminations, cost of ovulation synchronization for first service, and cost of the re-insemination according to whether heifers were re-inseminated at detected estrus or at fixed time. The collaborating herd weighed all heifers at $0,70,240$, and $300 \mathrm{~d}$ of age, every $2 \mathrm{wk}$ thereafter until the start of the ovulation synchronization protocol, and at approximately $600 \mathrm{~d}$ of age. Therefore, we were able to estimate the average daily BW gain from 330 to $600 \mathrm{~d}$ of age of all heifers in the herd. When a heifer was sold for slaughter we calculated the estimated BW according to their weight at enrollment and the age at culling. No heifers were sold for dairy purposes.

\section{Ultrasonography of Ovaries and Ovulation}

To evaluate the association between stage of the estrous cycle at the start of the ovulation synchronization protocol and ovulation in response to the first GnRH injection, a sub-sample $(\mathrm{n}=194)$ of heifers was selected randomly within week of start of the ovulation synchronization protocol (metestrus $=48$, early diestrus $=49$, mid diestrus $=79$, proestrus $=18)$. Ovaries of heifers were examined by ultrasound (Easi-Scan, $5 \mathrm{MHz}$; BCF technology, Rochester, MN) at the time of the first GnRH and $\mathrm{PGF}_{2 \alpha}$ injections. Heifers with a follicle $\geq 10$ $\mathrm{mm}$ in diameter on the day of the first $\mathrm{GnRH}$ injection and a new corpus luteum $\geq 15 \mathrm{~mm}$ in diameter on the day of the first $\mathrm{PGF}_{2 \alpha}$ injection were considered to have ovulated in response to the first GnRH.

\section{Statistical Analyses}

This was a completely randomized experimental design of 3 treatments. Heifers were randomized according to their average daily BW gain from 240 to $330 \mathrm{~d}$ of age. To detect a 7 percentage point difference in $\mathrm{P} / \mathrm{AI}$ between SSEarly and SSLate treatments (46 vs. 53\%), a total of 400 heifers/treatment were needed to prevent type I $(\alpha=0.05)$ and type II $(\beta=0.20)$ error.

All statistical analyses were carried out in SAS (SAS/ STAT version 9.4; SAS Institute Inc., Raleigh, NC). Binary outcomes were analyzed by logistic regression using the LOGISTIC procedure. The ilink logit function was used to calculate the adjusted means and standard error of the means. Time-dependent data were analyzed by Cox proportional hazard ratio using the PHREG procedure. Heifers were right censored when they did not have the outcome of interest (pregnancy, calving) before leaving the herd or were lost to follow-up. The Kaplan-Meier survival analysis, using the LIFETEST procedure, was used to plot the interval from enrollment to the outcome of interest when appropriate. Continuous data were analyzed by ANOVA using the MIXED procedure. Count data (e.g., number of inseminations) were analyzed by negative binomial regression using the GENMOD procedure.

To evaluate the effect of treatment on $\mathrm{P} / \mathrm{AI}$ and pregnancy loss to the first service, the models included treatment (CONV, SSEarly, SSLate), sire (A, B, C), type of breeding (estrus vs. timed AI), technician of AI (A, B), and the interaction between treatment and type of breeding. Furthermore, using only data from heifers inseminated at detected estrus, we included in the models the interval from onset of estrus to AI and the interaction between treatment and the interval from onset of estrus to AI. To understand the association between estrus-cycle stage at the start of the ovulation synchronization protocol and $\mathrm{P} / \mathrm{AI}$ and pregnancy loss to the first service we added to the models the estruscycle stage (metestrus, early diestrus, mid diestrus, and proestrus).

To test the effect of treatment on interval between first and second AI, number of inseminations, hazard of pregnancy, hazard of calving, culling, age at culling, estimated BW at culling, offspring characteristics, and cost at the end of the experiment, the models included treatment, sire, type of breeding for first service, and the interaction between treatment and type of breeding.

To evaluate the association between stage of the estrus-cycle at the start of the ovulation synchronization protocol and ovulation in response to the first $\mathrm{GnRH}$ and estrus characteristics, the model only included estrus-cycle stage.

The Tukey-Kramer adjustment was used to control for multiple hypotheses testing. A difference was declared at $P \leq 0.05$ and a tendency was declared at 0.05 $<P \leq 0.10$.

\section{RESULTS}

No differences $(P \geq 0.78)$ were observed among treatments regarding $\mathrm{BW}(\mathrm{CONV}=382.4 \pm 0.7$, SSEarly $=$ $382.4 \pm 0.7$, SSLate $=382.5 \pm 0.7 \mathrm{~kg})$ and age $(\mathrm{CONV}$ $=12.08 \pm 0.04$, SSEarly $=12.00 \pm 0.04$, SSLate $=$ $12.04 \pm 0.04 \mathrm{mo}$ ) at the start of the ovulation synchronization protocol. Similarly, no difference $(P=0.88)$ was observed among treatments regarding the estruscycle day at enrollment $(\mathrm{CONV}=11.0 \pm 0.3$, SSEarly $=11.2 \pm 0.3$, SSLate $=10.9 \pm 0.3 \mathrm{~d})$. The percentages of heifers in metestrus, early diestrus, mid diestrus, and proestrus at enrollment were, respectively, CONV 
$=19.2,20.5,35.4$, and 16.7\%; SSEarly = 16.6, 22.7, 35.9 , and 15.7\%; and SSLate $=18.4,20.7,37.8$, and $12.9 \%$. In addition, $8.2,9.2$, and $10.2 \%$ of heifers from the CONV, SSEarly, and SSLate treatments, respectively, were not detected in estrus before the start of the ovulation synchronization protocol or were detected in estrus $\geq 25 \mathrm{~d}$ before the start of the ovulation synchronization protocol.

\section{Effects of Treatment on Pregnancy to First Insemination}

A greater percentage of heifers in the SSLate treatment tended to be $(P=0.06)$ and was $(P=0.02)$ not detected in estrus compared with CONV and SSEarly treatments, respectively (Table 1). By design, heifers enrolled in the CONV and SSEarly treatments had $(P$ $<0.01$ ) shorter interval from onset of estrus to AI and from the GnRH injection to AI (Table 1). Among heifers detected in estrus, the ranges of the intervals from the onset of estrus to AI were 3.6 to $28.5 \mathrm{~h}, 0.0$ to 25.5 $\mathrm{h}$, and 9.4 to $36.8 \mathrm{~h}$ for the CONV, SSEarly, and SSLate treatments, respectively (Figure 2). Among heifers inseminated at fixed time, the ranges of the interval from the GnRH injection to AI were $0 \mathrm{~h}$ for heifers in the CONV and SSEarly treatments and 8.5 to 11.7 $\mathrm{h}$ for heifers in the SSLate treatment. Among heifers detected in estrus, the interval from the first $\mathrm{PGF}_{2 \alpha}$ treatment to the onset of estrus was not $(P=0.11)$ dif- ferent among treatments $(\mathrm{CONV}=51.9 \pm 0.5$, SSEarly $=51.6 \pm 0.5$, SSLate $=53.0 \pm 0.5$ h; Figure 3$)$.

The percentages of heifers that were diagnosed pregnant at $30 \pm 1$ and $62 \pm 1 \mathrm{~d}$ after first AI were $(P<$ 0.01) greater for the CONV treatment compared with the SSEarly and SSLate treatments (Table 1). Treatment did not $(P \geq 0.36)$ affect pregnancy loss from 30 \pm 1 to $62 \pm 1 \mathrm{~d}$ after the first $\mathrm{AI}$ and from $62 \pm 1 \mathrm{~d}$ after the first AI to calving. Heifers detected in estrus had $(P \leq 0.05)$ greater $\mathrm{P} / \mathrm{AI}$ at $30 \pm 1$ (estrus $=56.6$ \pm 1.7 , no estrus $=50.0 \pm 2.9 \%$ ) and $62 \pm 1$ (estrus $=54.3 \pm 1.7$, no estrus $=46.7 \pm 2.9 \%$ ) d after AI compared with those not detected in estrus. Expression of estrus, however, was not $(P \geq 0.18)$ associated with pregnancy loss from $30 \pm 1$ to $62 \pm 1 \mathrm{~d}$ and from $62 \pm$ $1 \mathrm{~d}$ to calving.

The interaction between treatment and interval from the onset of estrus to AI affected $(P<0.01) \mathrm{P} / \mathrm{AI}$ at $30 \pm 1$ and $62 \pm 1 \mathrm{~d}$ among heifers inseminated in estrus (Figure 4). This interaction was observed because among heifers enrolled in the CONV treatment, delaying insemination was associated with a slight decrease in the probability of pregnancy. Conversely, among heifers inseminated with sex-sorted semen, particularly in heifers enrolled in the SSEarly treatment, delaying the insemination increased the probability of pregnancy.

Among heifers conceiving and calving to the first AI, treatment did not affect the percentage of stillbirth $(P$ $=0.20)$ and twins $(P=0.86)$, but a larger percentage

Table 1. Effect of treatment on pregnancy per AI and offspring characteristics (first AI)

\begin{tabular}{|c|c|c|c|c|}
\hline Variable (土SEM) & $\begin{array}{c}\text { CONV }^{1} \\
(\mathrm{n}=390)\end{array}$ & $\begin{array}{l}\text { SSEarly }^{1} \\
(\mathrm{n}=415)\end{array}$ & $\begin{array}{l}\text { SSLate }^{1} \\
(\mathrm{n}=402)\end{array}$ & $P$-value \\
\hline Not detected in estrus, $\%$ & $24.4^{\mathrm{A}} \pm 2.2$ & $23.4^{\mathrm{a}} \pm 2.0$ & $31.6^{\mathrm{b}, \mathrm{B}} \pm 2.3$ & 0.02 \\
\hline Interval from onset of estrus to $\mathrm{AI}, \mathrm{h}$ & $12.6^{\mathrm{a}} \pm 0.3$ & $12.6^{\mathrm{a}} \pm 0.3$ & $23.3^{\mathrm{b}} \pm 0.3$ & $<0.01$ \\
\hline Interval from $\mathrm{GnRH}$ to insemination, $\mathrm{h}$ & $0.1^{\mathrm{a}} \pm 0.1$ & $0.1^{\mathrm{a}} \pm 0.1$ & $10.3^{\mathrm{b}} \pm 0.1$ & $<0.01$ \\
\hline \multicolumn{5}{|l|}{ Pregnancy per AI, \% } \\
\hline $30 \pm 1 \mathrm{~d}$ & $67.3^{\mathrm{a}} \pm 2.5$ & $45.2^{\mathrm{b}} \pm 2.6$ & $46.8^{\mathrm{b}} \pm 2.6$ & $<0.01$ \\
\hline $62 \pm 1 \mathrm{~d}$ & $63.1^{\mathrm{a}} \pm 2.6$ & $43.3^{\mathrm{b}} \pm 2.6$ & $44.8^{\mathrm{b}} \pm 2.7$ & $<0.01$ \\
\hline \multicolumn{5}{|l|}{ Pregnancy loss, $\%$} \\
\hline $30 \pm 1$ to $62 \pm 1 \mathrm{~d}$ & $5.6 \pm 1.4$ & $3.6 \pm 1.3$ & $3.6 \pm 1.4$ & 0.48 \\
\hline $62 \pm 1 \mathrm{~d}$ to calving & $6.5 \pm 1.6$ & $5.0 \pm 1.6$ & $8.7 \pm 2.1$ & 0.36 \\
\hline Calves from first service, no. & 223 & 167 & 162 & \\
\hline Stillbirth, \% & $8.9 \pm 2.0$ & $4.9 \pm 1.7$ & $5.3 \pm 1.7$ & 0.20 \\
\hline Twins, $\%$ & $1.8 \pm 0.9$ & $1.2 \pm 0.8$ & $1.2 \pm 0.9$ & 0.86 \\
\hline Female calf, $\%$ & $42.6^{\mathrm{a}} \pm 3.3$ & $89.2^{\mathrm{b}} \pm 2.4$ & $90.7^{\mathrm{b}} \pm 2.3$ & $<0.01$ \\
\hline Live female calf, $\%$ & $41.7^{\mathrm{a}} \pm 2.3$ & $89.2^{\mathrm{b}} \pm 2.4$ & $88.9^{\mathrm{b}} \pm 2.5$ & $<0.01$ \\
\hline Male calf, $\%$ & $57.4^{\mathrm{a}} \pm 3.3$ & $10.8^{\mathrm{b}} \pm 2.4$ & $9.3^{\mathrm{b}} \pm 2.3$ & $<0.01$ \\
\hline Live male calf, $\%$ & $48.9^{\mathrm{a}} \pm 3.4$ & $5.4^{\mathrm{b}} \pm 1.8$ & $4.9^{\mathrm{b}} \pm 1.7$ & $<0.01$ \\
\hline
\end{tabular}

${ }^{\mathrm{a}, \mathrm{b}}$ Means with different lowercase superscripts differ $(P \leq 0.05)$.

${ }^{\mathrm{A}, \mathrm{B}}$ Means with different uppercase superscripts tended to differ $(0.05<P<0.10)$.

${ }^{1}$ Heifers in the conventional (CONV) and early sex-sorted (SSEarly) semen treatments were inseminated $1 \mathrm{~h}$ after being determined to be in estrus, whereas heifers in the late sex-sorted (SSLate) semen treatment were inseminated 11 or $15 \mathrm{~h}$ after being determined to be in estrus. Heifers not detected in estrus received fixed-time insemination 1 (CONV and SSEarly treatments) and 11 (SSLate treatment) h after a GnRH (Fertagyl; Merck

Animal Health, Madison, NJ) injection. 


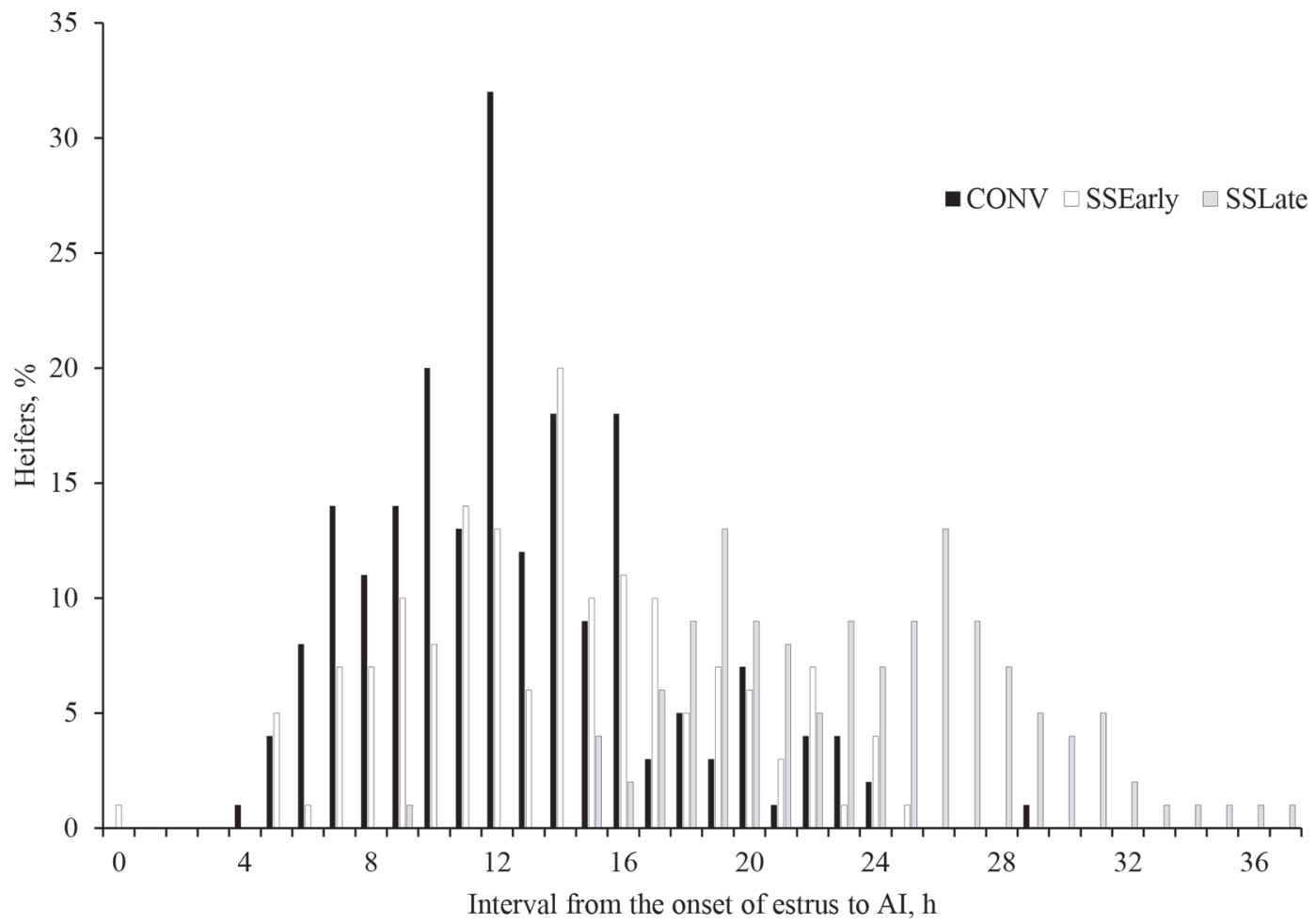

Figure 2. Effect of treatment on the interval from onset of estrus to AI $(P<0.01)$. CONV $=12.6 \pm 0.3 \mathrm{~h}$, SSEarly $=12.6 \pm 0.3 \mathrm{~h}$, SSLate $=$ $23.3 \pm 0.3 \mathrm{~h}$. Heifers in the conventional (CONV) and early sex-sorted (SSEarly) semen treatments were inseminated $1 \mathrm{~h}$ after being determined to be in estrus, whereas heifers in the late sex-sorted (SSLate) semen treatment were inseminated 11 or $15 \mathrm{~h}$ after being determined to be in estrus. Heifers not detected in estrus received fixed-time insemination 1 (CONV and SSEarly treatments) and 11 (SSLate treatment) h after a GnRH (Fertagyl; Merck Animal Health, Madison, NJ) injection.

of SSEarly and SSLate heifers delivered a female $(P$ $<0.01)$ and a live female $(P<0.01)$ calf (Table 1$)$. Conversely, a greater percentage of heifers enrolled in the CONV treatment calved a male $(P<0.01)$ and a live male $(P<0.01)$ calf (Table 1$)$.

\section{Effects of Treatment on Overall Reproductive and Economic Performances}

Treatment did not $(P=0.58)$ affect the interval between the first and second inseminations (Table 2). Heifers enrolled in the CONV treatment had $(P=0.03)$ fewer AI than heifers enrolled in the SSEarly treatment, but heifers enrolled in the SSLate treatment did not $(P \geq 0.15)$ differ from heifers enrolled in the CONV and SSEarly treatments (Table 2$)$. An effect $(P=0.03)$ of treatment on hazard of pregnancy was observed because heifers enrolled in the SSLate treatment had $(P$ $<0.01$ ) reduced hazard of pregnancy compared with heifers enrolled in the CONV treatment, but heifers enrolled in the SSEarly treatment did not $(P \geq 0.16)$ differ from heifers enrolled in the CONV and SSLate treatments (Table 2). Age at conception was $(P \leq 0.05)$ lesser for heifers enrolled in the CONV and SSEarly treatments than those enrolled in the SSLate treatment (Table 2; Figure 5). The hazard of calving and the age at calving were not $(P \geq 0.11)$ affected by treatment (Table 2; Figure 6). The percentage of heifers culled during the experiment tended to be $(P=0.08)$ lesser for the SSEarly than SSLate treatment, but CONV treatment did not $(P \geq 0.23)$ differ from the SSEarly and SSLate treatments (Table 2). Age at culling $(P=$ $0.58)$ and the estimated BW at culling $(P=0.52)$ were not different among treatments. Treatment did not $(P$ $\geq 0.86$ ) affect the percentage of heifers delivering stillbirth and twins, but SSEarly and SSLate heifers were $(P<0.01)$ more likely to deliver live female calves than CONV heifers (Table 2).

Although expression of estrus at first insemination was not associated with hazard of pregnancy [adjusted hazard ratio $(\mathbf{A H R})=1.12,95 \% \mathrm{CI}=0.98-1.28 ; P$ $=0.11]$ and hazard of culling $(\mathrm{AHR}=1.30,95 \% \mathrm{CI}$ $=0.88-1.9 ; P=0.19)$, heifers that expressed estrus at first AI had $(P<0.01)$ greater hazard of calving compared with heifers that did not express estrus (AHR = $1.24,95 \% \mathrm{CI}=1.08-1.42)$. The mean $( \pm \mathrm{SEM})$ ages at 


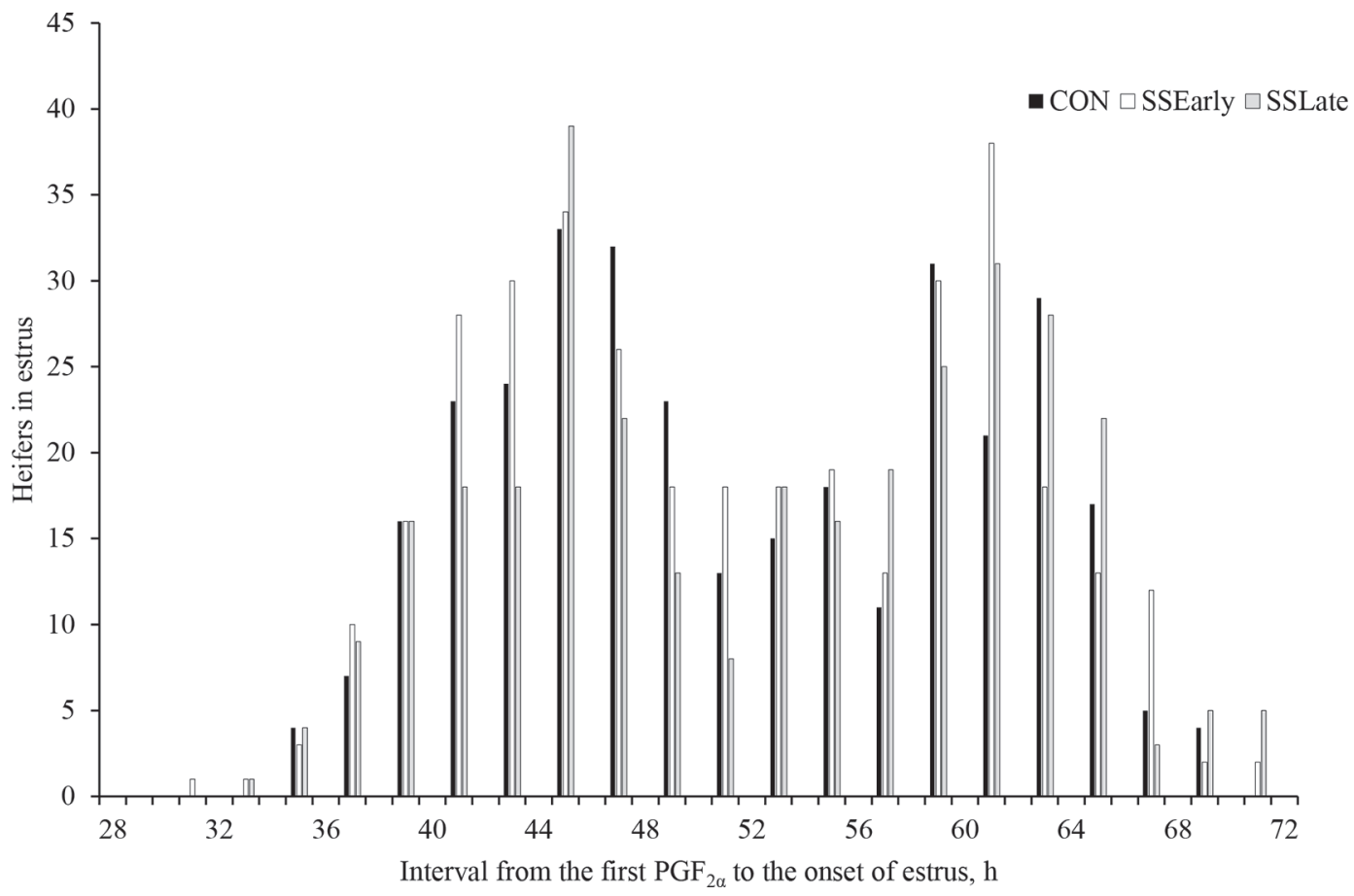

Figure 3. Distribution of the interval from $\mathrm{PGF}_{2 \alpha}$ (Estrumate; Merck Animal Health, Madison, NJ) treatment to the onset of estrus according to treatment. Heifers in the conventional (CONV) and early sex-sorted (SSEarly) semen treatments were inseminated $1 \mathrm{~h}$ after being determined to be in estrus, whereas heifers in the late sex-sorted (SSLate) semen treatment were inseminated 11 or $15 \mathrm{~h}$ after being determined to be in estrus. Heifers not detected in estrus received fixed-time insemination 1 (CONV and SSEarly treatments) and 11 (SSLate treatment) $\mathrm{h}$ after a GnRH (Fertagyl; Merck Animal Health, Madison, NJ) injection.

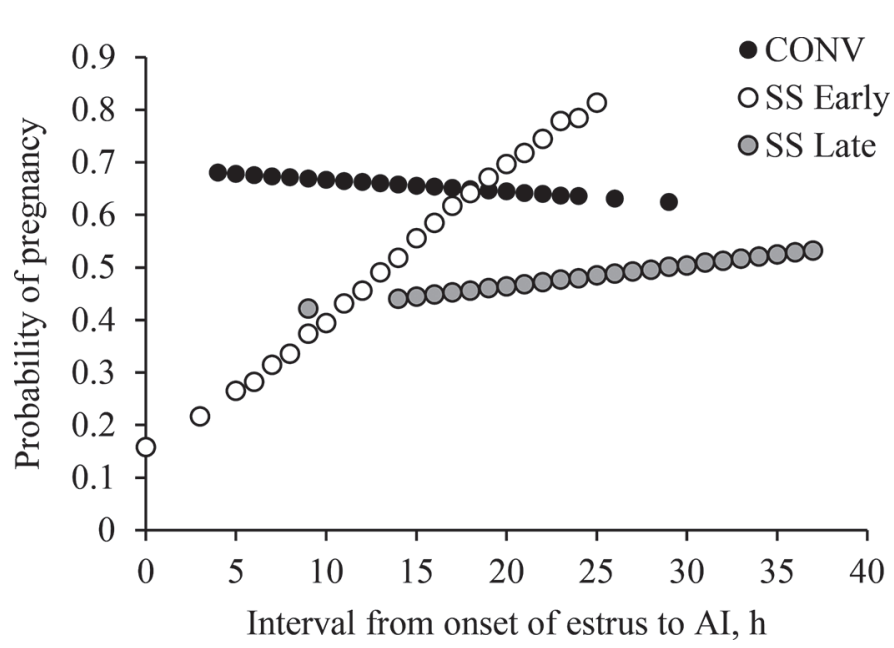

Figure 4. Effects of treatment and interval from onset of estrus to AI on the probability of pregnancy. Treatment $(P<0.01)$, interval from onset of estrus to $\mathrm{AI}(P<0.01)$, and the interaction between treatment and the interval from onset of estrus to AI $(P<0.01)$ Heifers in the conventional (CONV) and early sex-sorted (SSEarly) semen treatments were inseminated $1 \mathrm{~h}$ after being determined to be in estrus, whereas heifers in the late sex-sorted (SSLate) semen treatment were inseminated 11 or $15 \mathrm{~h}$ after being determined to be in estrus. Heifers not detected in estrus received fixed-time insemination 1 (CONV and SSEarly treatments) and 11 (SSLate treatment) h after a GnRH (Fertagyl; Merck Animal Health, Madison, NJ) injection. calving were $22.2 \pm 0.1$ and $22.6 \pm 0.1$ mo for heifers detected in estrus at first AI and heifers not detected in estrus at first AI, respectively.

According to the different scenarios that were created, the CONV treatment was the least costly from enrollment to first calving compared with the SSEarly and SSLate treatments when the values of 1-d-old female and male calves were $\$ 0$ and the cost of a replacement heifer was $\$ 750$ (Table 3). Conversely, when the values of 1 -d-old female and male calves were $\geq \$ 130$ and $\geq \$ 30$, respectively, and the value of replacement heifers was $\geq \$ 1,000$, no differences $(P \geq 0.37)$ were observed in the cost from enrollment to first calving among treatments (Table 3). In Figure 7 we demonstrate that, in the average of the 9 scenarios, the main sources of revenue were culling and female calves and the major costs were rearing and replacement.

\section{Association Between Estrus-Cycle Stage at Enrollment and Characteristics of Estrus and Pregnancy}

The percentage of heifers that ovulated in response to the first GnRH injection of the ovulation synchronization protocol was $(P<0.01)$ associated with the estrus- 


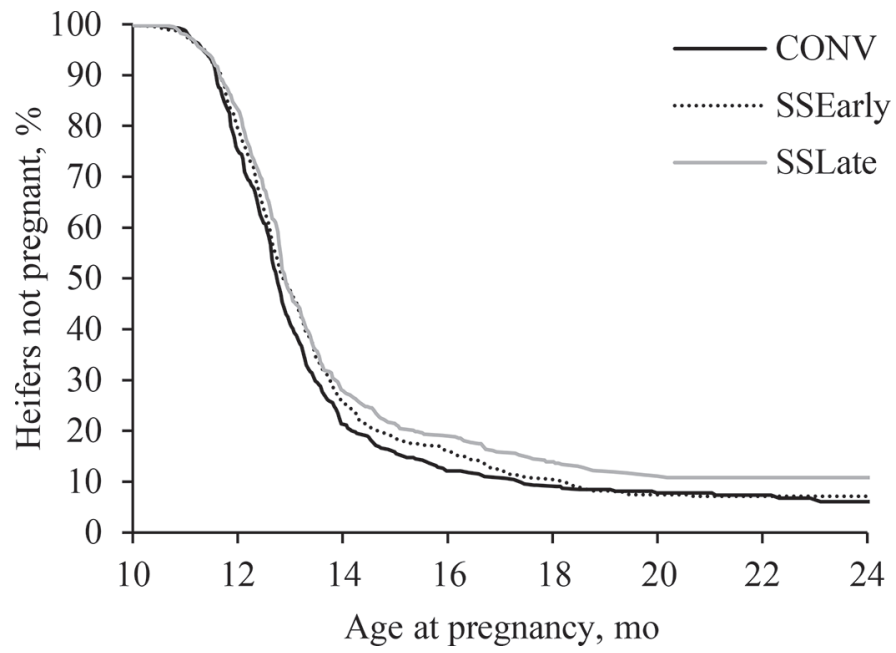

Figure 5. Effect of treatment on mean $( \pm$ SEM $)$ and median age at pregnancy $(P=0.04)$. CONV $=13.8 \pm 0.2$ and $12.8 \mathrm{mo}$, SSEarly $=$ $13.8 \pm 0.1$ and $12.9 \mathrm{mo}$, SSLate $=14.0 \pm 0.1$ and 12.9 mo. Heifers in the conventional (CONV) and early sex-sorted (SSEarly) semen treatments were inseminated $1 \mathrm{~h}$ after being determined to be in estrus, whereas heifers in the late sex-sorted (SSLate) semen treatment were inseminated 11 or $15 \mathrm{~h}$ after being determined to be in estrus. Heifers not detected in estrus received fixed-time insemination 1 (CONV and SSEarly treatments) and 11 (SSLate treatment) h after a GnRH (Fertagyl; Merck Animal Health, Madison, NJ) injection.

cycle stage at enrollment because heifers enrolled in mid diestrus were $(P<0.01)$ and tended $(P=0.08)$ to be less likely to ovulate compared with heifers enrolled in early diestrus and metestrus, respectively. Hazard of estrus after the first $\mathrm{PGF}_{2 \alpha}$ injection was $(P<0.01)$ greatest for heifers enrolled at proestrus, whereas heif-

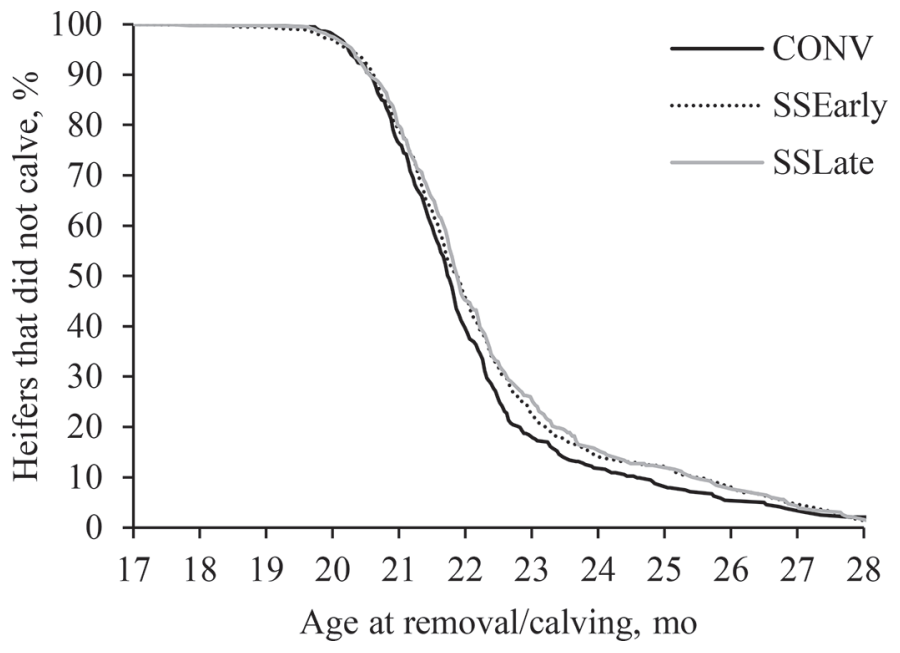

Figure 6. Effect of treatment on mean $( \pm \mathrm{SEM})$ and median age at calving or removal from the herd $(P=0.11)$. CONV $=22.2 \pm 0.1$ and $21.7 \mathrm{mo}$, SSEarly $=22.4 \pm 0.1$ and $21.9 \mathrm{mo}$, SSLate $=22.4 \pm 0.1$ and $21.9 \mathrm{mo}$. Heifers in the conventional (CONV) and early sex-sorted (SSEarly) semen treatments were inseminated $1 \mathrm{~h}$ after being determined to be in estrus, whereas heifers in the late sex-sorted (SSLate) semen treatment were inseminated 11 or $15 \mathrm{~h}$ after being determined to be in estrus. Heifers not detected in estrus received fixed-time insemination 1 (CONV and SSEarly treatments) and 11 (SSLate treatment) h after a GnRH (Fertagyl; Merck Animal Health, Madison, NJ) injection.

ers enrolled at mid diestrus tended $(P=0.06)$ to have greater hazard of estrus compared with heifers enrolled at early diestrus (Table 4). Heifers enrolled at early diestrus had $(P<0.01)$ the greatest interval from the first $\mathrm{PGF}_{2 \alpha}$ injection to estrus (Figure 8). Fewer heifers

Table 2. Effect of treatment on performance and offspring characteristics

\begin{tabular}{|c|c|c|c|c|}
\hline Variable & $\begin{array}{c}\mathrm{CONV}^{1} \\
(\mathrm{n}=390)\end{array}$ & $\begin{array}{l}\text { SSEarly }^{1} \\
(\mathrm{n}=415)\end{array}$ & $\begin{array}{l}\text { SSLate }^{1} \\
(\mathrm{n}=402)\end{array}$ & $P$-value \\
\hline Interval between first and second $\mathrm{AI}, \mathrm{d}( \pm \mathrm{SEM})$ & $23.6 \pm 0.7$ & $23.0 \pm 0.5$ & $22.7 \pm 0.5$ & 0.58 \\
\hline Number of inseminations $( \pm$ SEM $)$ & $1.58^{\mathrm{a}} \pm 0.04$ & $1.82^{\mathrm{b}} \pm 0.03$ & $1.75 \pm 0.04$ & 0.03 \\
\hline Age at conception, mo $( \pm \mathrm{SEM})$ & $13.8^{\mathrm{a}} \pm 0.2$ & $13.8^{\mathrm{a}} \pm 0.1$ & $14.0^{\mathrm{b}} \pm 0.1$ & 0.04 \\
\hline Hazard of calving, AHR (95\% CI) & Referent & $0.89(0.77,1.04)$ & $0.88(0.76,1.03)$ & 0.20 \\
\hline Age at calving, mo $( \pm$ SEM $)$ & $22.2 \pm 0.1$ & $22.4 \pm 0.1$ & $22.4 \pm 0.1$ & 0.11 \\
\hline Total calves & 333 & 352 & 330 & \\
\hline Stillbirth, \% $( \pm \mathrm{SEM})$ & $6.6 \pm 1.4$ & $5.7 \pm 1.2$ & $5.8 \pm 1.3$ & 0.86 \\
\hline Twins, \% ( \pm SEM $)$ & $1.2 \pm 0.6$ & $0.9 \pm 0.5$ & $1.2 \pm 0.6$ & 0.88 \\
\hline Live females, $\%( \pm \mathrm{SEM})$ & $40.5^{\mathrm{a}} \pm 2.7$ & $65.8^{\mathrm{b}} \pm 2.5$ & $70.0^{\mathrm{b}} \pm 2.5$ & $<0.01$ \\
\hline Live males, \% $( \pm$ SEM $)$ & $52.6^{\mathrm{a}} \pm 2.7$ & $28.2^{\mathrm{b}} \pm 2.4$ & $24.2^{\mathrm{b}} \pm 2.4$ & $<0.01$ \\
\hline
\end{tabular}

${ }^{\mathrm{a}, \mathrm{b}}$ Means with different lowercase superscripts differ $(P \leq 0.05)$.

${ }^{\mathrm{A}, \mathrm{B}}$ Means with different uppercase superscripts tended to differ $(0.05<P \leq 0.10)$.

${ }^{1}$ Heifers in the conventional (CONV) and early sex-sorted (SSEarly) semen treatments were inseminated $1 \mathrm{~h}$ after being determined to be in estrus, whereas heifers in the late sex-sorted (SSLate) semen treatment were inseminated 11 or $15 \mathrm{~h}$ after being determined to be in estrus. Heifers not detected in estrus received fixed-time insemination 1 (CONV and SSEarly treatments) and 11 (SSLate treatment) h after a GnRH (Fertagyl; Merck Animal Health, Madison, NJ) injection.

${ }^{2} \mathrm{AHR}=$ adjusted hazard ratio. 


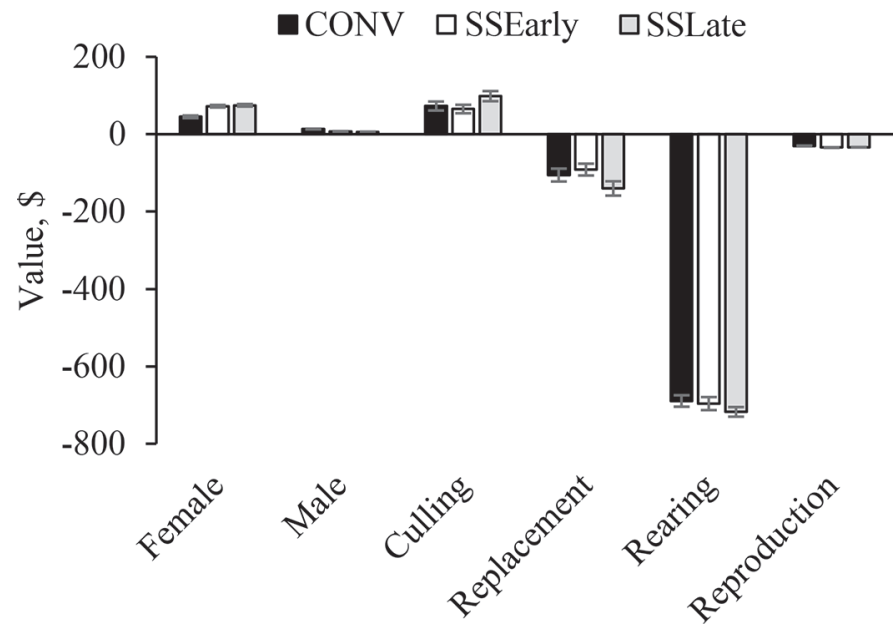

Figure 7. Effect of treatment on costs and revenues associated with raising heifers from enrollment to the first calving. Heifers in the conventional (CONV) and early sex-sorted (SSEarly) semen treatments were inseminated $1 \mathrm{~h}$ after being determined to be in estrus, whereas heifers in the late sex-sorted (SSLate) semen treatment were inseminated 11 or $15 \mathrm{~h}$ after being determined to be in estrus. Heifers not detected in estrus received fixed-time insemination 1 (CONV and SSEarly treatments) and 11 (SSLate treatment) $\mathrm{h}$ after a GnRH (Fertagyl; Merck Animal Health, Madison, NJ) injection. Error bars $( \pm$ SEM).

enrolled at early diestrus were detected in estrus by 72 $\mathrm{h}$ after the first $\mathrm{PGF}_{2 \alpha}$ injection compared with heifers enrolled in mid diestrus and proestrus $(P<0.01$; Table 4). Duration of estrus was $(P<0.02)$ shorter for heifers enrolled at metestrus compared with heifers enrolled during early diestrus and mid diestrus, but heifers enrolled in proestrus did not $(P \geq 0.33)$ differ from heifers enrolled at the other stages of the estrous cycle (Table 4$)$. Peak activity was $(P<0.01)$ lesser for heifers enrolled in metestrus compared with heifers enrolled in all other stages of the estrous cycle, and heifers enrolled in early diestrus had a tendency $(P=0.08)$ for reduced peak activity compared with heifers enrolled in mid diestrus (Table 4). Rumination nadir at estrus was $(P=0.05)$ greater for heifers enrolled at metestrus compared with heifers enrolled at mid diestrus. Heat index was not $(P=0.44)$ associated with stage of the estrous cycle at enrollment.

Pregnancy per AI at $30 \pm 1 \mathrm{~d}$ was $(P=0.04)$ and tended to be $(P=0.06)$ lesser for heifers enrolled in mid diestrus compared with heifers enrolled in early diestrus and metestrus, respectively (Table 4). At 62 $\pm 1 \mathrm{~d}$ after $\mathrm{AI}, \mathrm{P} / \mathrm{AI}$ was $(P \leq 0.03)$ lesser for heifers enrolled in mid diestrus compared with heifers enrolled in metestrus and early diestrus (Table 4). Pregnancy per AI at $30 \pm 1(P \geq 0.52)$ and $62 \pm 1(P \geq 0.22) \mathrm{d}$ after AI for heifers enrolled in proestrus did not differ from heifers enrolled in other stages of the estrous cycle. Although there was a tendency $(P=0.08)$ for estrus-cycle stage at enrollment to be associated with pregnancy loss from $30 \pm 1$ to $62 \pm 1 \mathrm{~d}$ after AI, estruscycle stage at enrollment was not $(P=0.98)$ associated with pregnancy loss from $62 \pm 1 \mathrm{~d}$ after AI to calving (Table 4).

\section{DISCUSSION}

The interval between onset of estrus and AI is critical for the successful establishment of pregnancy (Dransfield et al., 1998). Greatest P/AI with conventional semen is achieved when AI takes place 4 to $16 \mathrm{~h}$ after the onset of estrus because there is sufficient time for capacitation of spermatozoa before ovulation, which

Table 3. Effect of treatment on economic return per heifer enrolled in the experiment ${ }^{1}$

\begin{tabular}{|c|c|c|c|c|c|c|c|c|c|}
\hline \multirow[b]{2}{*}{ Scenario } & \multicolumn{2}{|c|}{ Semen, $\$$} & \multirow{2}{*}{$\begin{array}{l}\text { Replacement } \\
\quad \text { cost },{ }^{2} \$\end{array}$} & \multicolumn{2}{|c|}{$\begin{array}{l}\text { Value of live } \\
\text { calf, } \$\end{array}$} & \multicolumn{3}{|c|}{ Economic return per heifer, $\$ \pm$ SEM } & \multirow{2}{*}{$\frac{\text { TRT }}{P \text {-value }}$} \\
\hline & Conventional & Sex-sorted & & Female & Male & $\mathrm{CONV}^{3}$ & SSEarly $^{3}$ & SSLate $^{3}$ & \\
\hline 2 & 10.00 & 11.50 & 750 & 0 & 0 & $-764.2^{\mathrm{a}} \pm 7.1$ & $-791.6^{\mathrm{b}} \pm 7.0$ & $-779.6 \pm 6.8$ & 0.02 \\
\hline 3 & 15.00 & 17.25 & 750 & 0 & 0 & $-772.2^{\mathrm{a}} \pm 7.2$ & $-801.6^{\mathrm{b}} \pm 7.1$ & $-789.2 \pm 7.0$ & $<0.01$ \\
\hline 4 & 5.00 & 5.75 & 1,000 & 130 & 30 & $-716.4 \pm 8.7$ & $-715.0 \pm 8.5$ & $-716.7 \pm 8.6$ & 0.99 \\
\hline 7 & 5.00 & 5.75 & 1,500 & 260 & 60 & $-706.2 \pm 16.7$ & $-675.0 \pm 16.3$ & $-700.0 \pm 16.4$ & 0.37 \\
\hline 8 & 10.00 & 11.50 & 1,500 & 260 & 60 & $-714.1 \pm 16.8$ & $-684.9 \pm 16.4$ & $-709.5 \pm 16.5$ & 0.41 \\
\hline 9 & 15.00 & 17.25 & 1,500 & 260 & 60 & $-721.9 \pm 16.9$ & $-694.7 \pm 16.5$ & $-719.0 \pm 16.6$ & 0.45 \\
\hline
\end{tabular}

${ }_{\mathrm{a}, \mathrm{b}}$ Means with different superscripts differ $(P \leq 0.05)$.

${ }^{1}$ Fixed values: rearing cost $=\$ 2.50 / \mathrm{d}$ per heifer; cost of fixed-time AI protocol $=\$ 12.50 /$ protocol; cull value $=\$ 1.32 / \mathrm{kg}$.

${ }^{2}$ Value of a pregnant heifer approximately $60 \mathrm{~d}$ before expected calving date.

${ }^{3}$ Heifers in the conventional (CONV) and early sex-sorted (SSEarly) semen treatments were inseminated $1 \mathrm{~h}$ after being determined to be in estrus, whereas heifers in the late sex-sorted (SSLate) semen treatment were inseminated 11 or $15 \mathrm{~h}$ after being determined to be in estrus. Heifers not detected in estrus received fixed-time insemination 1 (CONV and SSEarly treatments) and 11 (SSLate treatment) h after a GnRH (Fertagyl; Merck Animal Health, Madison, NJ) injection. 
occurs $28 \mathrm{~h}$ after onset of estrus (Dransfield et al., 1998; Stevenson et al., 2014). Therefore, when ovulation occurs, a viable pool of spermatozoa is available for fertilization of the oocyte. Pregnancy per AI with sex-sorted semen is reduced compared with $\mathrm{P} / \mathrm{AI}$ with conventional semen (Schenk et al., 2009; Sá Filho et al., 2013). A few possible reasons are the reduced number of spermatozoa $\left(2 \times 10^{6}\right.$ or $4 \times 10^{6}$ motile cells/dose vs. $20 \times 10^{6}$ motile cells/dose) and the damage to the spermatozoa during the sorting process (Rath et al., 2009; Schenk et al., 2009). Consequently, a reduced pool of spermatozoa is available for fertilization of the oocyte following AI with sex-sorted semen. It is important to note that, even when larger number of spermatozoa is used per inseminating dose, $\mathrm{P} / \mathrm{AI}$ with sex-sorted semen is reduced compared with $\mathrm{P} / \mathrm{AI}$ with conventional semen (DeJarnette et al., 2011; Thomas et al., 2017, 2019). In a review, Saacke (2008a) postulated that male sub-fertility could be defined as compensable seminal deficiency, when a bull requires greater inseminating dose to achieve maximum fertility, and uncompensable seminal deficiencies, when a bull has reduced fertility independent of the inseminating dose. Therefore, the detrimental effects of the sorting process may not be overcome by increasing the inseminating dose in all sires.

The management strategy proposed in the current experiment to improve the $\mathrm{P} / \mathrm{AI}$ of heifers inseminated with sex-sorted semen, namely delaying insemination by approximately $12 \mathrm{~h}$, did not improve $\mathrm{P} / \mathrm{AI}$. In the current experiment, the overall $\mathrm{P} / \mathrm{AI}$ of heifers inseminated with sex-sorted semen was $70 \%$ of the $\mathrm{P} / \mathrm{AI}$ of heifers inseminated with conventional semen. Our hypothesis was based on previous observational studies from our group (Bombardelli et al., 2016) and others (Sá Filho et al., 2010) that demonstrated that the P/AI with sex-sorted semen increased when the AI occurred between 20 and $40 \mathrm{~h}$ after the onset of estrus compared with AI between 4 and $16 \mathrm{~h}$ after the onset of estrus. Our working hypothesis was that, because the number of viable spermatozoa is decreased in sex-sorted semen, delaying the insemination of heifers with sex-sorted semen in relation to the start of estrus, thus inseminating them closer to ovulation, would increase the pool of viable spermatozoa present in the oviduct to fertilize the oocyte and result in greater $\mathrm{P} / \mathrm{AI}$. Although the timing of AI with conventional semen relative to ovulation is important for $\mathrm{P} / \mathrm{AI}$, its effects on fertilization rate and embryo quality are believed to be opposite (Dalton et al., 2001; Saacke, 2008b). Early insemination relative to onset of estrus, further away from ovulation, is believed to result in reduced fertilization rate and excellent embryo quality because it would result in scarcity of spermatozoa in the oviduct to fertilize the oocyte, but spermatozoa of excellent quality. Conversely, late insemination relative to the onset of estrus, closer to

Table 4. Association between estrus-cycle stage at the start of the ovulation synchronization protocol ${ }^{1}$ and hazard of estrus, estrous characteristics, and pregnancy per AI

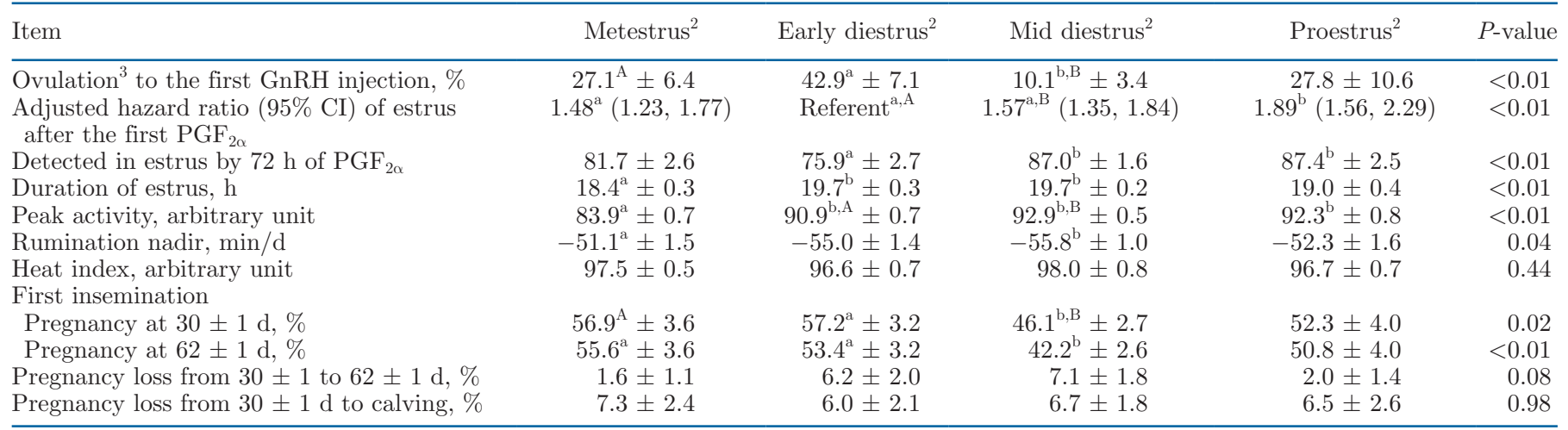

${ }^{\mathrm{a}, \mathrm{b}}$ Values within a row with different lowercase superscripts differ $(P \leq 0.05)$.

${ }^{\mathrm{A}, \mathrm{B}}$ Values within a row with different uppercase superscripts tend to differ $(0.05<P \leq 0.10)$.

${ }^{1}$ Heifers were subjected to the 5-d Cosynch protocol with a controlled internal drug release (CIDR; Zoetis, Parsippany-Troy Hills, NJ) insert. Day -8: GnRH (Fertagyl; Merck Animal Health, Madison, NJ) and CIDR insert; d -3: PGF $2 \alpha$ (Estrumate; Merck Animal Health, Madison, NJ) and CIDR insert removal; $\mathrm{d}-2: \mathrm{PGF}_{2 \alpha}$; and $\mathrm{d} 0$ : $\mathrm{GnRH}$ and fixed-time AI.

${ }^{2}$ Heifers $(n=1,096)$ were detected in estrus by the automated estrus-detection device $\leq 24$ d before the start of the ovulation synchronization protocol and were classified as being in metestrus ( 1 to $4 \mathrm{~d}$ after estrus; $\mathrm{n}=219$ ), early diestrus $(5$ to $9 \mathrm{~d}$ after estrus; $\mathrm{n}=257$ ), mid diestrus (10 to 17 d after estrus; $\mathrm{n}=438$ ), and proestrus (18 to $24 \mathrm{~d}$ after estrus; $\mathrm{n}=182$ ) at the start of the ovulation synchronization protocol. Sixteen heifers were detected in estrus $\geq 25 \mathrm{~d}$ before the start of the ovulation synchronization protocol (range: 25 to $40 \mathrm{~d}$ ) and 95 heifers were not detected in estrus before the start of the ovulation synchronization protocol.

${ }^{3} \mathrm{~A}$ sub-sample $(\mathrm{n}=194)$ of heifers was randomly selected within week of start of the ovulation synchronization protocol (metestrus $=48$, early diestrus $=49$, mid diestrus $=79$, proestrus $=18$ ) and was examined by ultrasound on $\mathrm{d}-8$ and -3 . Heifers with a follicle $\geq 10$ mm in diameter on $\mathrm{d}-8$ and a new corpus luteum $\geq 15 \mathrm{~mm}$ in diameter on $\mathrm{d}-3$ were considered to have ovulated in response to the first $\mathrm{GnRH}$. 
ovulation, is believed to result in greater fertilization rate and lesser embryo quality because a large pool of spermatozoa would be available to fertilize the oocyte, but the oocyte may be aged by the time that spermatozoa are able to fertilize it. Little is known about the effects of different intervals between AI with sex-sorted semen and ovulation on fertilization of oocytes and embryo quality of cattle.

The design of the current experiment was such that this strategy, if successful, could be implemented in commercial dairies. Although this strategy would be feasible in commercial herds, it resulted in a wide range of intervals from the onset of estrus to insemination $(\mathrm{CONV}=3.6$ to $28.5 \mathrm{~h}$, SSEarly $=0.0$ to $25.5 \mathrm{~h}$, SSLate $=9.4$ to $36.8 \mathrm{~h}$ ). This wide range of intervals from onset of estrus to AI may have affected our ability to determine differences among treatments. The interaction between treatment and type of AI did not affect the P/AI, but it is noteworthy that $\leq 32 \%$ (n $\leq$ $127 /$ treatment) of heifers did not display estrus in the current experiment and were subjected to timed AI. Thomas et al. (2014) demonstrated that the P/AI of suckled beef cows AI with sex-sorted semen increased when the timed AI was delayed by $20 \mathrm{~h}$. When we evaluated the association between the interval from onset of estrus to AI we noticed that the $\mathrm{P} / \mathrm{AI}$ of heif-

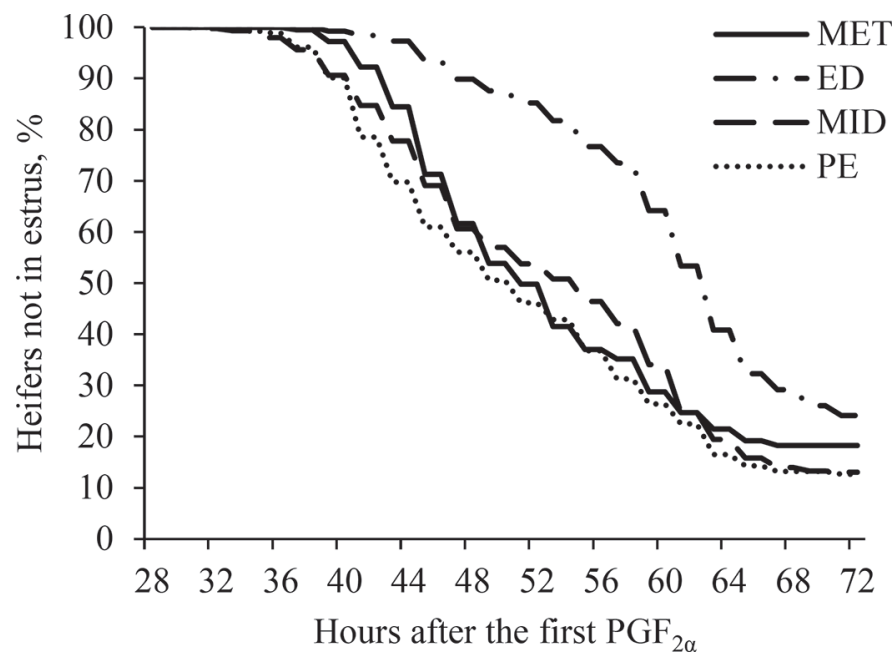

Figure 8. Association between estrus-cycle stage and rate at which heifers displayed estrus $(P<0.01)$. The mean $( \pm$ SEM $)$ and median intervals from the first $\mathrm{PGF}_{2 \alpha}$ (Estrumate; Merck Animal Health, Madison, NJ) injection to estrus were metestrus (MET; heifers starting the ovulation synchronization protocol between 1 and $4 \mathrm{~d}$ after estrus; $\mathrm{n}=219)=53.4 \pm 0.6$ and $51 \mathrm{~h}$, early diestrus (ED; heifers starting the ovulation synchronization protocol between 5 and $9 \mathrm{~d}$ after estrus; $\mathrm{n}=257)=61.6 \pm 0.5$ and $63 \mathrm{~h}$, mid diestrus (MID; heifers starting the ovulation synchronization protocol between 10 and $17 \mathrm{~d}$ after estrus; $\mathrm{n}=438)=53.9 \pm 0.5$ and $55 \mathrm{~h}$, and proestrus $(\mathrm{PE}$; heifers starting the ovulation synchronization protocol between 18 and 24 $\mathrm{d}$ after estrus; $\mathrm{n}=182)=52.3 \pm 0.8$ and $51 \mathrm{~h}$. ers in the CONV treatment slightly decreased as the interval increased, whereas the $\mathrm{P} / \mathrm{AI}$ increased as the interval from onset of estrus to AI increased among heifers in the SSEarly and SSLate treatments. These findings suggest that AI of heifers with sex-sorted semen should not take place $<14 \mathrm{~h}$ after the onset of estrus, otherwise a more dramatic loss in fertility compared with AI with conventional semen may occur. Sales et al. (2011) demonstrated that inseminating Jersey heifers with conventional semen 6.5 versus $12.5 \mathrm{~h}$ before presumptive ovulation did not affect $\mathrm{P} / \mathrm{AI}$, but greater $\mathrm{P} / \mathrm{AI}$ was observed among heifers inseminated with sex-sorted at 6.5 versus $12.5 \mathrm{~h}$ before presumptive ovulation. In addition, the $\mathrm{P} / \mathrm{AI}$ of Jersey heifers were fewer when they were AI with sex-sorted semen 12 to $16 \mathrm{~h}$ after the onset of estrus and was greatest when they were AI between 16.1 and $24 \mathrm{~h}$ after the onset of estrus (Sá Filho et al., 2013). Postponing AI with sex-sorted semen raises questions about the ability of spermatozoa to undergo capacitation and how it may affect fertilization of oocyte and embryo quality. Although some researchers have suggested that the sexsorting process may induce capacitation-like changes in spermatozoa in vitro (Maxwell et al., 1996, 1998), others have maintained that there is no evidence that the sex-sorting process induces premature capacitation (Bucci et al., 2012). In the current experiment, a 12-h delay in AI with sex-sorted semen did not reduce $\mathrm{P} /$ AI, indicating that capacitation may not be a limiting factor when delaying AI with sex-sorting semen.

Not surprisingly, the partial budget analysis demonstrated that, when the values of 1-d-old female and male calves are $\$ 0$, which would represent a condition of excess replacement heifers, and the value of a replacement heifer is $\$ 750$, the SSEarly treatment resulted in greater cost per heifer enrolled compared with the CONV treatment. Conversely, when the values of a 1 -d-old female calf was $\geq \$ 130$, 1 -d-old male calf was $\geq \$ 30$, and replacement heifer was $\geq \$ 1,000$, no differences among treatments in cost per heifer enrolled were observed. These findings reflect the fact that the differences among treatments regarding hazard of calving and age at first calving were minimal and the fact that insemination with sex-sorted produced a larger number of live female calves. As expected, the largest cost from enrollment in the reproductive program to first calving was rearing and the largest sources of revenue were culling and female calves.

Although the current experiment was not designed to test whether the stage of the estrous cycle at the start of the ovulation synchronization protocol would affect $\mathrm{P} / \mathrm{AI}$, we investigated this association. In the current experiment, heifers that were enrolled in the ovulation synchronization protocol during metestrus (d 
1 to 4 of the estrous cycle) and early diestrus (d 5 to 9 of the estrous cycle) had greater P/AI than heifers enrolled during mid diestrus (d 10 to 17 of the estrous cycle). It is widely accepted that the start of GnRHbased ovulation synchronization protocols between $\mathrm{d}$ 5 and 9 of the estrous cycle of lactating dairy cows increases P/AI because of the larger proportion of cows that ovulate in response to the first GnRH injection of the protocol (Vasconcelos et al., 1999) and consequent improvements in embryo quality (Cerri et al., 2009). The ovarian responses of heifers to $\mathrm{GnRH}$ according to stage of the estrous cycle (Moreira et al., 2000) are similar to the responses of lactating dairy cows. In the current experiment, start of the ovulation synchronization protocol during metestrus and early diestrus was associated with greater percentage of heifers ovulating to the first GnRH compared with those starting the protocol at mid diestrus, which could explain why they had greater P/AI. Although the percentage of heifers ovulating to the first GnRH did not differ among heifers starting the ovulation synchronization protocol in the proestrus, metestrus, and early diestrus, starting the protocol in the proestrus may reduce the synchrony of luteolysis and ovulation at the end of the protocol (Vasconcelos et al., 1999; Moreira et al., 2000). Surprisingly, the $\mathrm{P} / \mathrm{AI}$ of heifers starting the ovulation protocol in the proestrus, however, was not different than the $\mathrm{P} /$ AI of heifers starting the protocol at other stages of the estrous cycle. In a recent experiment, Karakaya-Bilen et al. (2019) demonstrated that presynchronization of heifers with $\mathrm{PGF}_{2 \alpha} 10 \mathrm{~d}$ before the start of the ovulation synchronization protocol improves $\mathrm{P} / \mathrm{AI}$ largely because of increased ovulation to the first GnRH injection of the protocol and perhaps because of improved ovulation at the end of the protocol. Our findings suggest that ovulation synchronization protocols for fixed time AI for heifers should not be initiated between d 10 and 17 of the estrous cycle.

\section{CONCLUSIONS}

The proposed strategy to improve P/AI of heifers inseminated with sex-sorted semen (delaying the AI by approximately $12 \mathrm{~h}$ ) was not successful. Although it is difficult to determine the exact causes, we believe that the range of intervals from the onset of estrus to AI within treatments was too wide, limiting our ability to properly test whether delaying $\mathrm{AI}$ in $12 \mathrm{~h}$ would improve $\mathrm{P} / \mathrm{AI}$. In fact, we observed that, in heifers enrolled in the SSEarly treatment, AI $<14 \mathrm{~h}$ after the onset of estrus resulted in very few $\mathrm{P} / \mathrm{AI}$, whereas later $\mathrm{AI}$ was associated with greater $\mathrm{P} / \mathrm{AI}$. Other experiments are necessary to test this hypothesis when $100 \%$ of heifers are inseminated at fixed time and the $\mathrm{GnRH}$ injection is given $16 \mathrm{~h}$ earlier than in the current experiment to reduce the number of heifers in estrus and the variability in the interval from onset of estrus to AI. Despite the lesser P/AI for the SSEarly and SSLate treatments, the differences in economic return among treatments were small or null because the interval from enrollment to calving was not different among treatments and because SSEarly and SSLate treatments resulted in a greater number of live female calves. Finally, our results suggest that it may be possible to increase the P/AI of heifers submitted to an ovulation synchronization protocol by presynchronizing their estrous cycle and increasing the proportion of them that are in metestrus and early diestrus at the start of the ovulation synchronization protocol.

\section{ACKNOWLEDGMENTS}

The authors thank the Florida Milk Producers' Milk Check-Off program for partially funding this project. We extend our gratitude to the owners and staff of Brooksco Dairy Farm (Quitman, GA) for their collaboration. We thank Zoetis (Parsippany-Troy Hills, NJ) for supplying CIDR inserts and Merck Animal Health (Madison, NJ) for supplying $\mathrm{GnRH}$ and $\mathrm{PGF}_{2 \alpha}$. The authors have not stated any conflicts of interest.

\section{REFERENCES}

Bombardelli, G. D., H. F. Soares, and R. C. Chebel. 2016. Time of insemination relative to reaching activity threshold is associated with pregnancy risk when using sex-sorted semen for lactating Jersey cows. Theriogenology 85:533-539. https://doi.org/10.1016/ j.theriogenology.2015.09.042.

Bucci, D., G. Galeati, C. Tamanini, C. Vallorani, J. E. Rodriguez-Gil, and M. Spinaci. 2012. Effect of sex sorting on CTC staining, actin cytoskeleton and tyrosine phosphorylation in bull and boar spermatozoa. Theriogenology 77:1206-1216. https://doi.org/10.1016/j .theriogenology.2011.10.028.

Carvalho, J. O., R. Sartori, G. M. Machado, G. B. Mourão, and M. A. Dode. 2010. Quality assessment of bovine cryopreserved sperm after sexing by flow cytometry and their use in in vitro embryo production. Theriogenology 74:1521-1530. https://doi.org/10.1016/j .theriogenology.2010.06.030.

Cerri, R. L., H. M. Rutigliano, R. C. Chebel, and J. E. Santos. 2009. Period of dominance of the ovulatory follicle influences embryo quality in lactating dairy cows. Reproduction 137:813-823. https:/ /doi.org/10.1530/REP-08-0242.

Dalton, J. C., S. Nadir, J. H. Bame, M. Noftsinger, R. L. Nebel, and R. G. Saacke. 2001. Effect of time of insemination on number of accessory sperm, fertilization rate, and embryo quality in nonlactating dairy cattle. J. Dairy Sci. 84:2413-2418. https://doi.org/10 .3168/jds.S0022-0302(01)74690-5.

DeJarnette, J. M., M. A. Leach, R. L. Nebel, C. E. Marshall, C. R. McCleary, and J. F. Moreno. 2011. Effects of sex-sorting and sperm dosage on conception rates of Holstein heifers: is comparable fertility of sex-sorted and conventional semen plausible? J. Dairy Sci. 94:3477-3483. https://doi.org/10.3168/jds.2011-4214.

DeJarnette, J. M., C. R. McCleary, M. A. Leach, J. F. Moreno, R. L. Nebel, and C. E. Marshall. 2010. Effects of 2.1 and 3.5x10(6) sex-sorted sperm dosages on conception rates of Holstein cows and 
heifers. J. Dairy Sci. 93:4079-4085. https://doi.org/10.3168/jds $.2010-3181$.

Dransfield, M. B., R. L. Nebel, R. E. Pearson, and L. D. Warnick. 1998. Timing of insemination for dairy cows identified in estrus by a radiotelemetric estrus detection system. J. Dairy Sci. 81:18741882. https://doi.org/10.3168/jds.S0022-0302(98)75758-3.

FASS. 2010. Guide for the care and use of agricultural animals in research and teaching. 3rd ed. FASS Inc., Champaign, IL.

Gosálvez, J., M. A. Ramirez, C. López-Fernández, F. Crespo, K. M. Evans, M. E. Kjelland, and J. F. Moreno. 2011a. Sex-sorted bovine spermatozoa and DNA damage: I. Static features. Theriogenology 75:197-205. https://doi.org/10.1016/j.theriogenology.2010.08.006.

Gosálvez, J., M. A. Ramirez, C. López-Fernández, F. Crespo, K. M. Evans, M. E. Kjelland, and J. F. Moreno. 2011b. Sex-sorted bovine spermatozoa and DNA damage: II. Dynamic features. Theriogenology 75:206-211. https://doi.org/10.1016/j.theriogenology .2010.09.011.

Karakaya-Bilen, E., G. Yilmazbas-Mecitoglu, A. Keskin, B. Guner, E. Serim, J. E. P. Santos, and A. Gümen. 2019. Fertility of lactating dairy cows inseminated with sex-sorted or conventional semen after Ovsynch, Presynch-Ovsynch and Double-Ovsynch protocols. Reprod. Domest. Anim. 54:309-316. https://doi.org/10.1111/rda .13363 .

Lima, F. S., E. S. Ribeiro, R. S. Bisinotto, L. F. Greco, N. Martinez, M. Amstalden, W. W. Thatcher, and J. E. P. Santos. 2013. Hormonal manipulations in the 5-day timed artificial insemination protocol to optimize estrous cycle synchrony and fertility in dairy heifers. J. Dairy Sci. 96:7054-7065. https://doi.org/10.3168/jds .2013-7093.

Maxwell, W. M., C. R. Long, L. A. Johnson, J. R. Dobrinsky, and G. R. Welch. 1998. The relationship between membrane status and fertility of boar spermatozoa after flow cytometric sorting in the presence or absence of seminal plasma. Reprod. Fertil. Dev. 10:433-440. https://doi.org/10.1071/RD98102.

Maxwell, W. M., G. R. Welch, and L. A. Johnson. 1996. Viability and membrane integrity of spermatozoa after dilution and flow cytometric sorting in the presence or absence of seminal plasma. Reprod. Fertil. Dev. 8:1165-1178. https://doi.org/10.1071/ RD9961165.

Moreira, F., R. L. de la Sota, T. Diaz, and W. W. Thatcher. 2000. Effect of day of the estrous cycle at the initiation of a timed artificial insemination protocol on reproductive responses in dairy heifers. J. Anim. Sci. 78:1568-1576. https://doi.org/10.2527/2000.7861568x.

Rath, D., G. Moench-Tegeder, U. Taylor, and L. A. Johnson. 2009. Improved quality of sex-sorted sperm: A prerequisite for wider commercial application. Theriogenology 71:22-29. https://doi.org/10 .1016/j.theriogenology.2008.09.027.

Sá Filho, M. F., H. Ayres, R. M. Ferreira, M. Nichi, M. Fosado, E. P. Campos Filho, and P. S. Baruselli. 2010. Strategies to improve pregnancy per insemination using sex-sorted semen in dairy heifers detected in estrus. Theriogenology 74:1636-1642. https://doi.org/ 10.1016/j.theriogenology.2010.06.036.

Sá Filho, M. F., M. F. Mendanha, R. V. Sala, F. J. Carvalho, L. H. Guimarães, and P. S. Baruselli. 2013. Use of sex-sorted sperm in lactating dairy cows upon estrus detection or following timed artificial insemination. Anim. Reprod. Sci. 143:19-23. https://doi.org/ 10.1016/j.anireprosci.2013.10.014.
Saacke, R. G. 2008a. Sperm morphology: Its relevance to compensable and uncompensable traits in semen. Theriogenology 70:473-478. https://doi.org/10.1016/j.theriogenology.2008.04.012.

Saacke, R. G. 2008b. Insemination factors related to timed AI in cattle. Theriogenology 70:479-484. https://doi.org/10.1016/j theriogenology.2008.04.015.

Sales, J. N., K. A. Neves, A. H. Souza, G. A. Crepaldi, R. V. Sala, M. Fosado, E. P. Campos Filho, M. de Faria, M. F. Sá Filho, and P. S. Baruselli. 2011. Timing of insemination and fertility in dairy and beef cattle receiving timed artificial insemination using sex-sorted sperm. Theriogenology 76:427-435. https://doi.org/10 .1016/j.theriogenology.2011.02.019.

Schenk, J. L., D. G. Cran, R. W. Everett, and G. E. Seidel Jr.. 2009. Pregnancy rates in heifers and cows with cryopreserved sexed sperm: Effects of sperm numbers per inseminate, sorting pressure and sperm storage before sorting. Theriogenology 71:717-728. https://doi.org/10.1016/j.theriogenology.2008.08.016.

Seidel, G. E. Jr. 2003. Economics of selecting for sex: The most important genetic trait. Theriogenology 59:585-598. https://doi.org/10 .1016/S0093-691X(02)01242-6.

Silva, T. V., F. S. Lima, W. W. Thatcher, and J. E. Santos. 2015. Synchronized ovulation for first insemination improves reproductive performance and reduces cost per pregnancy in dairy heifers. J. Dairy Sci. 98:7810-7822. https://doi.org/10.3168/jds.2015-9704.

Stevenson, J. S., S. L. Hill, R. L. Nebel, and J. M. DeJarnette. 2014 Ovulation timing and conception risk after automated activity monitoring in lactating dairy cows. J. Dairy Sci. 97:4296-4308. https://doi.org/10.3168/jds.2013-7873.

Thomas, J. M., S. L. Lock, S. E. Poock, M. R. Ellersieck, M. F. Smith, and D. J. Patterson. 2014. Delayed insemination of nonestrous cows improves pregnancy rates when using sex-sorted semen in timed artificial insemination of suckled beef cows. J. Anim. Sci. 92:1747-1752. https://doi.org/10.2527/jas.2013-7131.

Thomas, J. M., J. W. C. Locke, R. C. Bonacker, E. R. Knickmeyer, D. J. Wilson, R. Vishwanath, A. M. Arnett, M. F. Smith, and D. J. Patterson. 2019. Evaluation of SexedULTRA 4M ${ }^{\mathrm{TM}}$ sex-sorted semen in timed artificial insemination programs for mature beef cows. Theriogenology 123:100-107. https://doi.org/10.1016/j .theriogenology.2018.09.039.

Thomas, J. M., J. W. C. Locke, R. Vishwanath, J. B. Hall, M. R. Ellersieck, M. F. Smith, and D. J. Patterson. 2017. Effective use of SexedULTRA $^{\text {TM }}$ sex-sorted semen for timed artificial insemination of beef heifers. Theriogenology 98:88-93. https://doi.org/10.1016/ j.theriogenology.2017.03.018.

Vasconcelos, J. L., R. W. Silcox, G. J. Rosa, J. R. Pursley, and M. C. Wiltbank. 1999. Synchronization rate, size of the ovulatory follicle, and pregnancy rate after synchronization of ovulation beginning on different days of the estrous cycle in lactating dairy cows. Theriogenology 52:1067-1078. https://doi.org/10.1016/S0093 $-691 \mathrm{X}(99) 00195-8$.

\section{ORCIDS}

Ricardo C. Chebel ๑ https://orcid.org/0000-0002-9700-8089 Thiago Cunha @ https://orcid.org/0000-0003-4356-8651 